\section{We Agree!}

To the Editor: Dr. Redka's views are our views. Preparing the Personal Physician for Practice $\left(\mathrm{P}^{4}\right)$ is a consequence of the Future of Family Medicine Project conducted by 6 task forces; all task forces were populated with practicing clinicians. This pattern has been carried forward into the $\mathrm{P}^{4}$ project, with the steering committee including full-time family physicians as well as experienced family physicians now working in various roles in health care. It has been exciting to see several of the $\mathrm{P}^{4}$ residencies initiate experiments with community practices. The alignment of residency experimentation with practice redesign through TransforMED is not an accident but a commitment to joining what happens in residency with what is needed in practice.

Larry A. Green, MD

University of Colorado School of Medicine

Denver

Perry Pugno, MD, MPH, CPE

American Academy of Family Physicians

Leawood, KS

Gerald "Jay" Fetter, Jr, MSA

TransforMED, Association of Family Medicine

Residency Directors

Leawood, KS

Samuel M. Jones, MD

VCU-Fairfax Family Practice Center

Fairfax, VA

doi: 10.3122/jabfm.2007.06.070190

\section{Inpatient Care Is an Important Part of Family Medicine}

To the Editor: Dr. Whitcomb's ${ }^{1}$ suggestions for training family medicine residents in the continuing care of patients with chronic illnesses are excellent. Continuity of care with a panel of patients and problem-based learning around those patients are excellent alternatives to the disjointed collection of clinics, lectures, and specialty outpatient rotations that are often used to meet training requirements. However, his abandonment of inpatient training throws the baby out with the bathwater.
The role of a personal physician for the patient in the hospital is still a critical one. Hospitalist models do fulfill this role well in some settings and are an alternative for primary care physicians who choose to opt out of hospital care. However, many office-based generalists still find the time and maintain the expertise to provide highquality hospital care for their patients. Both physicians and patients often find this to be a much more satisfying and successful relationship than one where the patient is "handed off" to a hospital physician. In this era of 2-day admissions, step-down units, home health care, etc, transitions between these many settings are often best managed by a personal physician who is integrated into these systems. Furthermore, evidence suggests that while hospitalists may provide modest cost efficiency, they do not improve on the quality of care provided by community physicians. $^{2}$

It may well be time to examine how inpatient care is taught. Work hour rules, short stays, high patient volumes, and documentation requirements are certainly affecting how much medicine is being learned by inpatient residents. New models such as following continuity patients in the hospital may be a better alternative to some portion of traditional inpatient rotations. But taking family physicians out of the hospital will be a step away from providing patients with a true personal physician, and I see no evidence that family medicine is ready to, or should as a matter of quality, abandon hospital care.

Jeffrey Tiemstra, MD

Department of Family Medicine University of Illinois at Chicago Chicago

\section{References}

1. Whitcomb, ME. Preparing the personal physician for practice $\left(\mathrm{P}^{4}\right)$ : meeting the needs of patients: redesign of residency training in family medicine. J Am Board Fam Med 2007;20(4):356-64.

2. Everett G, Uddin N, Rudloff B. Comparison of hospital costs and length of stay for community internists, hospitalists, and academicians. J Gen Intern Med 2007;22(5):662-7.

doi: 10.3122/jabfm.2007.06.070168 